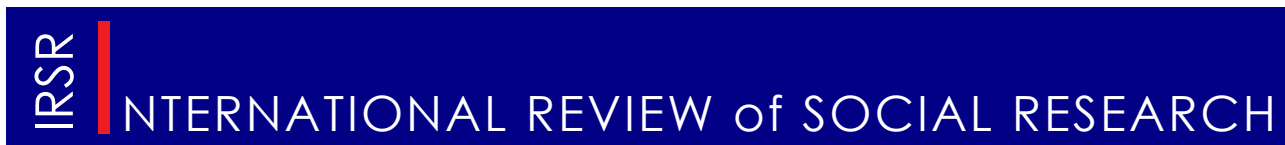

Volume 2, Issue 3, October 2012, 1-16

International Review of Social Research

\title{
Cosmopolitans, Spatial Mobility and the Alternative Geographies
}

\author{
Magdalena NOWICKA \\ Ludwig-Maximilian University Munich, Germany \\ Max Planck Institute for the Study of Ethnic and Religious Diversity
}

\begin{abstract}
This paper seeks to reframe the debates on cosmopolitanism and mobile cosmopolitan subjects by focusing its analysis on a multidimensional character of sociospatial relations. In particular, it critically engages with these works which too often see subjects as social categories and distinguish cosmopolitans from others, and which are silent about how people relate to space. The paper makes use of the study of mobile professionals working an international organization belonging to the United Nation family of organizations and argues that mobility in space creates a condition for emerging of sites of diversity and of new spatial imaginaries. It asks how these two aspects are related to each other. While the first aspect is addressed in the empirical studies, the paper makes a claim that cosmopolitanism is about challenging the latent spatial imaginaries and creating alternative geographies. Grounding this claim in empirical research, the paper complements the theoretical works on normative cosmopolitanism.
\end{abstract}

Keywords: cosmopolitanism, mobility, space, diversity, spatial imaginaries, United Nations.

\section{Introduction: mobilities, cosmopolitanism and space}

Geographical mobility has been relevant to the cosmopolitan debate in two ways: First, as the spread of knowledge, images and information with the help of global media. This aspect concerns ways of thinking about the world as a whole and expanding the capacity to compare different places and people (Szerszynski and Urry, 2006). On the other hand, these visual mobilities lead to the emergence of the global as a frame of reference for local action. Beck $(2002 ; 2004)$ relates this aspect of cosmopolitanism to 'banal globalism', which he understands as narratives and imaginaries of belonging to a single world community, where the absent and abstract other is always present in the local discourse and

e-mail: magdalena.nowicka@soziologie.uni-muenchen.de. 
practice. The empirical works dedicated to this perspective, for example, show the emerging of cosmopolitan empathy when images of suffering in distant sites induce particular humanitarian actions elsewhere (Kurasawa, 2009).

Second, mobility is relevant in terms of physical movement of people and objects of various kinds. It is the unobstructed movement, among others, of persons across national frontiers, that constitutes the condition of cosmopolitanization (Beck, 2004: 135). Delanty (2006: 32) complements that mobility of people is important for this 'banal cosmopolitanism' as it transforms the ties of culture and place and thus modes of cultural belonging. Vertovec (2009: 5) defines cosmopolitanism similarly 'as comprising a combination of attitudes, practices and abilities gathered from experiences of travel or displacement'.

Thereby, the links between the two kinds of mobilities and the two approaches are unclear. Are these simultaneous but parallel processes or is there any causality between them? Does the competence to deal on the ground, in daily interactions, with people of different cultural, ethnic, social and national backgrounds translate into an abstract idea of the world as a whole? Does anybody feeling attuned with the world have a competence to act in a cosmopolitan way in daily encounters? In other worlds: how can the abstract worldly outlooks - and the mundane cosmopolitan practices - be reconciled in a theory of cosmopolitanism?

I address these questions through researching mobile people - migrants and frequent travelers who work for an institution belonging to the 'United Nations family of organizations', and asking how they conceive of global space. I look at their practices of mobility and the relations they develop to people in local sites, and I ask how they construct their mental maps of the world. Finally, I argue that mobility has a potential for challenging established spatial imaginaries and plead for an understanding of cosmopolitanism as a process of confrontation of the latent geographies.

In relation to mobility, much of the literature has focused on identifying cosmopolitan subjects - people that are capable of cosmopolitan outlooks and practice, in contrast to those, who are not. Two positions have been taken so far: first which views a cosmopolitan competence as an ability to travel and consume the non-local and exotic 'out there' (Calhoun, 2003), and second, which is critical of the classbias of the first and which identifies cosmopolitans among ordinary people whose everyday reality requires them to display a worldly sensibility and openness towards others (Lamont and Aksartova, 2002; Werbner 1999; Burawoy et al., 2000). This reality has itself become 'cosmopolitanised' (Beck, 2004), the process which has been fuelled by global mobility of images, persons and ideas (Appadurai, 1996). This condition produces 'mundane cosmopolitans' (Hebdige, 1990; Skrbis and Woodward, 2007: 731). Both positions, though, view subjects as social categories cosmopolitan or not-cosmopolitan (Hannerz, 1990) - and understand cosmopolitanism as an individual quality of people, a particular attitude towards otherness that they possess, and the practice in which it manifest.

For both perspectives space is 
relevant, although sometimes just implicitly, first as a local site where actual cosmopolitan practice can take place, and second, as a global realm in which commodities, people and ideas travel almost freely. The first approach thus sees space as a concrete, physical site which can be loaded with different symbolic meanings; the second is underpinned by an abstract notion of space (Casey, 1998; Massey, 2005). My aim is to link the two perspectives. I ask how encounters with ethnic and cultural diversity in local sites translate into geographical imaginaries of mobile people.

In following, I focus on a group of mobile professionals who are both migrants and frequent travelers. I draw here on an empirical study which I conducted among professionals employed in one of the organizations being a part of the 'United Nations family' (Nowicka, 2006). The study consisted of in-depth interviews with thirteen individuals conducted between February 2003 and September 2004 and analyzed with the paradigm of the Grounded Theory (Strauss and Corbin, 1990; Glaser, 1978; 1998; 2001). Its aim was to make an explanatory contribution to our knowledge of daily practices of highly-skilled professional individuals in respect of how they make use and construct different spaces such as home, and how this teaches us of space in the era of reflexive modernization (Nowicka, 2006; 2007; 2008). This study focused on daily routines and perceptions but it did not consider the question of cosmopolitan practices or orientations.
Mobility, sites of diversity and cosmopolitans

Mobility of people, knowledge, images, and all kinds of goods creates a particular condition of socio-cultural diversity, which is then perceptible by the mind and senses in particular local spaces such as cities, or neighborhood. Most authors agree that this is a condition for individuals to develop a cosmopolitan disposition (Skrbis and Woodward, 2007: 732). Cosmopolitanism is viewed here as a mode of coping with this diversity, of bridging socio-cultural difference dayto-day.

Although most frequently related to the novelty of technological developments in travel, this notion of cosmopolitanism has its sources in times of discovery and expansion in the European Renaissance and Enlightenment. In particular, the firstwave colonization of Latin America brought forth discussion on the idea of man transcending the division between citizen and foreigner (Mignolo, 2000: 727). Colonialism brought about legions of diplomats, educators, administrators, traders and technocratic experts to colonized lands. Common to those traveling bodies was a discourse of travel as a key to self-enhancement and worldly outlook (Belk, 1997). Scientific travels, for example those of Georg Foster, in the eighteenth century, involved a systematic investigation of unknown people and places and the question of the richness of cultures in the world (Kleingeld, 1999). On the other hand, the intellectuals of the late Enlightenment were engaging critically in dialogue with the colonial restructuring of the world, 
some of them- most prominently Goethe - sharply condemning the colonial exploitation (Noyes, 2006). Cosmopolitanism was linked with the issues of different forms of bodily travel (colonialism, scientific discovery, mass tourism, migration) and to the consequent encounters with the others.

This classical cosmopolitanism is associated with elitism insofar as it was mostly European cultural elites who regarded travel to distant destinations as a mode of personality formation in terms of cultivation of worldliness through training in foreign languages and knowledge of art and culture (Thompson and Tambyah, 1999: 217). This association of cosmopolitanism and mobile elites pertains until nowadays in relation to the global capitalist class members and their transnational life-styles who symbolically constitute their social group via exclusive cultural codes that transcend particularized contexts (Calhoun, 2003; Jones, 2007). We may think of Castells' informationrich financial elites freed from local and national bindings (Castells, 1996), Sklair's transnational capitalist class acting beyond national borders and alliances (Sklair, 2001), Kanter's business cosmopolitans who know how to use local resources globally (Kanter, 1995), Hannerz's foreign correspondents who desire to foster their audiences' experience of being at home in the world (Hannerz, 2004) or artistic avant gardes and their transcending cultures beyond the local (Werbner, 2008). However, this kind of cosmopolitan competence is increasingly being assigned to non-Western and non-elite hosts (Bayly, 2007; Lamont and Aksartova,
2002). Central to these approaches is the assumption that the physical co-presence of people of different cultural backgrounds necessitates a mode of coping with this difference, and that - under certain conditions cosmopolitanism is such a mode.

In this context also, cities are increasingly considered 'cosmopolitan' sites of 'nomadic civilization' where people from around the world and of different ethnic, religious and cultural backgrounds meet (Kahn, 1987). Sociological analyses of the cosmopolitan situation in cities are informed by the early twentiethcentury study of Georg Simmel (1908) on various modalities of presence of the Stranger and its multiple consequences for togetherness. But while for Simmel a Stranger was an extraordinary figure in otherwise relatively closed communities, the global condition makes a Stranger into a norm. The clue is a new dynamic of multiple opportunities for socializing created by people of different backgrounds, habits and outlooks, and for new modes of confronting a 'local stranger' (Werbner, 1999: 33). In this vane, ethnographic research investigates for example consumption of cultural goods and products and foods in particular local sites, and different modes of peaceful togetherness in super-diverse contexts (Wise and Velayutham, 2009; Hiebert, 2002). This research stresses non-elite and non-European cosmopolitanisms (Bhabha, 1996; Werbner, 2002). For these ordinary people ethnic and cultural difference is not a reason for excluding the others (Appiah, 2006), at least not in public and parochial spaces (Wessendorf, 2010). 
Mobile professionals and the limits to a cosmopolitan practice

In super-diverse sites space matters insofar it offers different opportunities of contact and therefore for a cosmopolitan practice (Wise and Velayutham, 2009). Thereby fleeting encounters are as meaningful as deeper engagements with 'others' (Vertovec, 2009). Spaces which are very diverse - in terms of gathering products, foods or people originating in different corners of the globe force people to pragmatically navigate around these differences (Noble, 2009; Wessendorf, 2010). Scholars researching cosmopolitanism turn therefore their attention exactly to such sites where they are more likely to identify cosmopolitan subjects and practices than elsewhere.

In contrast, I focused my study on mobile people which enables me to look at how space matters for cosmopolitanism from a slightly different angle. Also, the fact that people I studied are members of the 'UN family' - the organization that includes the cosmopolitan ideal in its mission and for whom cosmopolitanism is a part of their working creed (Held, 2002; 2001), enables me to show a tension between the cosmopolitan aspirations and identities of the mobile professionals and their actual practices in different spaces.

The nature of the UN's mission necessitates a particular organizational structure: a network of local offices worldwide and global distance communication structures. The professionals and staff of the UN come from more than 190 states. The UN's policy on mobility, implemented as a general rule in 2008, considers mobility (between geographical locations and departments) a desirable feature enabling exchange of knowledge and, therefore, improving the quality of work. Changing work assignments involves a different scope of responsibilities, a new environment, new colleagues, and new destination countries. Having worked in Europe or the United States they have a chance to work next in Africa, Asia or Latin America.

The specific employment conditions are reflected in the composition of the research sample. The 13 interviewees come from 11 different countries and had lived for at least six months on average in five countries in their lifetime. They were aged 31 to 63 and in average around 40 years old. Six women and seven men were interviewed; nine people among them were married, two lived in a partnership, one was widowed and one single. Ten people had children. All of them spoke at least 1 foreign language, at maximum five, at a level of proficiency or as a mother tongue.

The professionals I studied undertook a position in an international organization for several reasons. Those who entered the organization as young university graduates in the 1970s were often interested in the issues of development and desired to help people. They also wanted to experience new people and their cultures from a position of someone who is geographically and emotionally close to them. Younger people aspired to a prestigious job or simply grabbed a chance. Many of them studied abroad and searched for international employment opportunities for the 
sake of their own career development. Notwithstanding these differences, common to all the informants is a certain curiosity and intrinsic interest in distant places, people and cultures.

My informants stay in one location for a couple of years before moving to another country. They move with their immediate families, who offer them emotional nearness; thus, they may not feel compelled to find new friends. Most of the individuals interviewed currently live in a country in which the official spoken language is not their native language, and where the possibility of socializing depends on how widely English is spoken. The specific conditions of employment involve an extensive support of the employer towards re-settlers on how to make the process of moving household and family less frustrating and less time-consuming. This includes advising on schooling for children, spouse career, housing, and child and elderly care. Voluntary staff networks provide guidance on living conditions, cultural customs, and religious beliefs and practice on the host country, and they mediate between the new settlers and families of staff members already residing in the locality. All this might lead to a certain dependency from the organization and its staff members, which obviously quarrels with the desire to engage with locals and their culture.

The international professionals I studied are highly motivated to discover new people and places and to understand their lives, desires and problems for professional reasons. Being in place, meeting people and seeing how the international aid projects influence their lives lets the studied professionals feel satisfied with own efforts and see the sense of their support (Nowicka, 2006: 105ff; 2008). Another reason is a curiosity for 'otherness'. They expect to find great diversity in the surrounding world, yet, as Diego explains, they also find similarity and universal rules and structures:

Two things that are surprising when you move across...at least my own experience moving across these very different countries has been that on the one hand how similar they are and on the other hand that as similar as they appear to be on ninety five percent of the issues how different they can be on the other five percent. So that's the very interesting thing. Yes, they are different, yes, they are not as different one thinks they are, 'cause on most things they tend to be quite similar but for those small percentages that are different, differences are big.

On the other hand, Diego is convinced that if countries were completely different, it would be more difficult (for him) 'to make an adjustment' when resettling. Serious differences between countries could 'put [his] family and [his] world upside down', he notices. Further, he reveals:

I think, what is happening today is that you are able to go to countries as diverse as this [Saudi Arabia and Slovenia] and if you do not want to be exposed to any of these differences, if you are not someone to deal with them, there are ways to completely shut them off...you could completely avoid the local...you are able to almost 
consciously decide how much exposure do I really want to have to local things.

How do international professionals 'regulate their exposure' to the locals and the localities? I looked closer at their foreign language skills, social networks, use of schooling, housing and shopping opportunities and spare time activities. I noticed certain mechanisms, which my interviewees more or less consciously use to minimize or maximize the number and duration of encounters with the local difference.

Regarding the language, Ann, for example, notices that she never actually comes into direct contact with the locals, because someone translates everything for her: in business these are professional interpreters, in personal issues she is assisted by her colleagues. The other interviewees tell the same sort of story: they 'manage the situation'. As Martin points out, 'everybody speaks enough English for you to survive'. Our interview partners may avoid speaking a local language by shopping in supermarkets, where they take food or other products from a shelf not having to know their names or to ask a salesclerk. 'I manage in a taxi and in a shop, and after all the shops here are mostly supermarkets anyway', says Ann. They also choose to go to opera or to concerts instead of theatre because 'they are very accessible (...) the language does not matter' and 'in cinema there are subtitles' (Interview with Ann).

Moreover, the interviewees' social networks are very international (comp. Kennedy, 2009). Friendships are a matter of 'chemistry between people' (Interview with Lenka), and this is the case when two people share similar interests and problems and not ethnicity. Usually, these are other international professionals and expatriates, who face similar challenges in a foreign country. Lenka notices, 'somehow foreigners stick together'.

In terms of housing, the people I studied tend to reside in Western compounds which offer them security and a certain living standard to which they are used. Houses and flats rented to foreigners are usually fully furnished, which is convenient for those, who move for few years to a country. In Eastern Europe, they live in quite luxurious and expensive areas, inhabited by many foreigners. They can afford such housing, and they prefer it because of short distance to facilities like international schools and kindergartens, or fitness and golf clubs.

International schools attended by the interviewees' children are a common platform for meeting new people. Expatriate communities offer a friendly environment, certain familiarity and support for new settlers. However, the interviewees claim to feel alienation and estrangement if their social networks and activities are unintentionally restricted to this single environment (Beaverstock 2002). Lack of time is as much a reason for this as missing language skills and the opportunity structures. The interviewees' hobbies are individualized: they do indoor and outdoor sports that do not require them to coordinate with others, for example power walking, and which can also be exercised anywhere. A favourite hobby of many informants is to be at home: to spend time together with the family, do some works in the garden, cook 
together, take care of the household.

Several informants are interested in arts and regularly attend exhibitions or visit interesting architectural sites. One-day or weekend trips are very popular among the interviewees. When they have visitors, they show them around the country and its most popular cultural sites. Some are very conscious about the limited time they have to discover the attractions and particularities of their new country of residence and try to see as much of it as possible. Less reflectively, the interviewees enjoy short distances in Europe to discover neighbouring countries; some take a plane to go shopping in London or Paris, or attend a particularly interesting event in any European capital, for example a theatre play. Residents in Africa and Asia visit national parks to admire a distinct nature. Thus, they often behave like tourists, whom Hannerz (1990) contrasted with cosmopolitans: they consume places; they get to know few locals; they try out 'exotic' dishes. They remain at the surface, which stays in contradiction to their own selfdescriptions (Nowicka and Kaweh, 2009).

Despite their aspirations to engage in encounters with 'others', they may often find themselves in a situation when they cannot expose themselves to 'local things'. They are aware of the danger of a 'missing an opportunity' offered by an overseas assignment (Thompson and Tambyah, 1999); yet they are confronted with many constraints that include language barrier or time shortages due to heavy work load and frequent short business travels. The necessity to maintain contact to family that is dispersed across many countries poses a dilemma to them, whether to go abroad to meet old friends and family members or to spend more time in a locality where they can make new friends.

Physical constrains such as diverse digestive system diseases may also lead to an unintended closure towards the locals and their culture. They are quite common in many countries and they disable travellers who may need to take several precautions to avoid them; these include taking medications and avoiding certain foods and drinks which the locals eat daily. Frequent travellers are making themselves fit to travel, which can be considered a part of a general cosmopolitan competence (Molz, 2006). However, there is another side to securing their own safety: someone who, for the sake of his wealth, eats in expensive restaurants and never uses a bus or walks on the streets in places with high criminality is indeed much detached from the locals, who may lack means of such protection or develop alternative competence to cope with the risks at daily basis. I term this a 'human limit' to cosmopolitanism - moments, in which people reach a physical or emotional limit of experiencing 'otherness' by direct, physical encounters. Space matters here again, but in a different way: highly dense places, such as India, where people constantly touch other people when passing by (Interview with Margret) or dirty places (Interview with Lenka), limit the scope of cosmopolitan interactions.

However, also in this case we can identify moments of openness, which are enforced by the local conditions. Atanas, for example, recalls his travels to Kazakhstan, where he could reach 
the UN project site only by horse; he slept in tents weeks long without running water and a toilet. These primitive conditions brought him closer to the locals, he learned from them and became a bit alike them, at least in respect of personal hygiene. In this sense, he was forced to open himself and to 'fit' into this particular local condition (Molz, 2006). Reiner, who lived several years in Africa, taught his children at home; bad roads and no facilities made him focusing his social life on home, which was common to the locals as well. Also, the ways these mobile professionals gather knowledge about the place of residence is a one not available to most local residents. They acquire it not from television programmes, not during private chats with friends, but during official meetings, when talking to politicians and experts, reading reports, or attending conferences. Indeed, they have a deep sense of the country's history, the problems of the local economy, social problems, and they are up-to-date with the country's political situation.

The local opportunity structures, such as the availability of international schools and kindergartens, supermarkets or fitness centres, concert halls and cinemas, and the personal mobility trajectories, shape the nature encounters with diversity and the possibilities and limits of a cosmopolitan practice as a reaction to it. In practice, the moments of openness and closely followed by the moments of closure. On the other hand, the studied professionals exercise a competence to socialize across national and ethnic divide within their professional milieu.

\section{Spatial imaginaries}

Does coping with ethnic and cultural difference in daily life translates into a more abstract imaginative of the world as a whole, or imaginative challenging of the world order based on attributive, highly territorialised, ethnic and national categories? I argue that mobility has a potential both to produce modes of peaceful togetherness and the alternative geographies which are the key element of cosmopolitanism. Let me explain this claim starting with contrasting two imaginaries: national and cosmopolitan, and then moving to the empirical material to demonstrate how such alternative cosmopolitan geography of mobile professionals looks like.

The everyday geography of encounters with difference is grounded in a set of representations and images of the world (Harvey, 2000). The national imaginary is that of divided spatial units, of similarity and difference that are marked by a number of physical and symbolic boundaries. Spaces based on a regional logic enclose similar elements (where similarity is achieved by suppression of differences) within fixed boundaries. Within such spaces what is similar is close, what is different is far. Social or individual characteristics can be territorialized and associated with a particular geographic entity. A population, for instance that of a nation, may map onto a geographic region, for example, a territory of a nation state or a population with primary education can map onto the continent Africa. Regionalism enforces easy associations, for example between poor and uneducated, Africa and disease. Such associations may be 
mobilized to depict the population, for example Africans as unruly, decaying, chaotic and hopeless (Comaroff, 1993). They can be powerful tools of exclusion and discrimination. Within the 'national order of things' (Malkki, 1997), they take a form of stereotypes, for example of 'a normal German' (Beck-Gernsheim, 2004: 171). The practice of mapping the social on geographical regions results in methodological nationalism (Beck, 2004a: 47). The national geographic follows the exclusive logic of eitheror (Beck, 2002b) as in Gellner's comparison of maps drawn under the principle of nationalism to the paintings of Modigliani: "neat flat surfaces are clearly separated from each other, it is generally plain where one begins and another ends, and there is little if any ambiguity or overlap' (Gellner, 1983: 140). The regional mapping is thus not about any difference but about sorting out the relevant difference. In the national framework, the difference is coded primarily into nationality. Different is someone who has a different nationality. A Stranger is someone who came from outside the state. The others are those, who live somewhere else. As nationality is composed of other attributes described as culture (language, habits, cuisine, etc.), the Others are also culturally different - they speak a different language, eat different food, etc.

Cosmopolitanism is thought of as an outlook and practice of transcending the territorial local and the national. The cosmopolitan imaginary is thus that of transcendence and wholeness. Can then frequent trespassing of regional boundaries lead to a new, cosmopolitan everyday geography? Certainly, the national order of things is still present and powerful (comp. Hiebert, 2002; Sassen, 1996); however, geographic mobility may explode the territorial reference of qualitative attributes. To prove this thesis I looked at how my informants construct socio-spatial divides. I paid attention to what they mean when they say 'Africa' or 'Europe' or 'Asia', and what kind of difference they consider relevant when drawing boundaries around such territorialized entities.

Discursively, my informants stress that the current global condition is one of borderlessness, of the world at reach (Brose, 2004: 7). They think nowadays no clear and rigid boundaries can be identified, and relations are not restricted by geographical distance. The national, territorial discourse tends to be replaced by the discourse of availability: spaces on both sides of a border are equally accessible to the mobile individuals, and this fact undermines the existence of solid boundaries more broadly. Borders neither regulate the flows, nor make a difference to day-to-day activities. It is irrelevant on which side of the border one is located. Indeed, my informants move within the networks rather than between the countries. These are networks of all kinds of infrastructures and people though which the 'regulate their exposure' to the local conditions as described above.

Nevertheless, my informants steadily compare places which they visit and in which they reside. Not all differences and similarities are relevant to them. They compare only certain aspects: those that are, for them, decisive about the quality of living. These are: 1) people, especially 
how open, friendly, and cooperative they are, whether it is easy to make friendships with them; all these determine a general climate in a place - a friendly or hostile atmosphere of living; 2) infrastructure: whether it is present, and its quality: spare time facilities (cinemas, theatres, and landscapes), living facilities (housing, schooling), general infrastructure (roads), security, etc., and 3) weather.

Inaddition, theintervieweescompare the level of economic development, measured both in economic indicators and in the availability and quality of infrastructure, political regimes, and relationships between authorities and population. All these factors relate to their job, and are, with some small exceptions, related to the whole country and not to the particular place of residence.

They compare with reference to their own place of origin or residence or travel destination. So they compare through the lenses of own experience in order to decide on the next or future place of residence. For example, Martin would not like to live in a place where the infrastructure is not sufficient, or where there are no cinemas or theatres, to which he is used in his country of origin and current place of residence. This type of comparison contains emotional elements: it expresses preferences and a lack of sympathy towards certain aspects that are different or similar.

Comparing, the interviewees establish mental clusters. So, for example, Reiner compared Kenya to Switzerland as 'the moon and the planet Earth', then Kenya and Nigeria 'there was not really a difference', and all these countries to the USA, when he could assign Kenya and Nigeria to one category, and Switzerland and the USA to a second. Similarly, Martin assigned the USA and Austria to one category, and distinguished it from the category of countries with insufficient infrastructure. Most interviewees combined Poland, Croatia, Latvia, Hungary, and Slovenia into one category of country, which are 'almost as developed as the Western countries', and also contrasted them with Africa.

The interviewees also compare people in different places. Such opinions usually contain statements about things that the interviewees find unusual or different. For example, Rodrigo thinks that people in Africa mistrust their governments; Ann thinks that people in Poland in the early nineties were sad and tired; Diego believes that Saudis are afraid of losing the homogeneity of their society, and Ludmila considers all people in Ukraine to be tall and handsome. The scope of factors that are considered in such statements is very broad - from appearance to attitudes. Made on the basis of very short encounters, they are projected on to the population of the country: the Ukrainians are handsome, the African mistrust the government, the Polish were sad, etc. Thereby, nationality is nothing more than a descriptive category. The interviewees always try to justify the behavior of the group, by citing current circumstances, and the political and historical background, or economic situation. Therefore, the Africans mistrust their governments because the authorities have often betrayed their trust, and the Poles were sad because their hopes relating to the political change did 
not improve their personal economic situation.

When talking about striking differences or unusual encounters with people, my interviewees always try to differentiate their opinions about particular individuals and the collectives. For example, Ann says: as a group, the IO employees are mistrusted, yet 'when you establish' contact at the individual level, 'you don't feel this mistrust'. According to Diego, people in Saudi Arabia are threatened by the idea of American and Western influence in their country. Yet this situation does not exclude the possibility of finding very good friends among the Saudis, or meeting people who are able to accept that there are some 'good things about the USA'. At the collective level, differences tend to be coded into nationality, or 'culture' (also national culture), but at the individual level nationality plays no role.

Because even in a worse population one can find friendly and trustworthy people, my interviewees do not consider people as a factor primarily influencing their decision to travel to or settle in a place. The opposite can be said of structural differences, such as infrastructure and political and economic conditions. Not only do they take on importance as an explanation for social differences, but they also play a key role in the choices of the mobile individuals.

Thus, the interviewees draw a kind of map of the world, which is quite different from and more complex than the nation-state order or the ethnic or cultural order, and it is indeed parallel to them. At this map, there are no borders but thresholds that mark discontinuity of practices which is due to different infrastructures. A threshold means a point of entering or beginning something, or a limit of reaction; it seems more appropriate to describe the points of passage from one spatial entity to another. The interviews provided many examples of such discontinuities. Somewhere between Europe and Asia, there is a threshold, before which the mobile individuals do not have to carry any medications, can eat any fruit, and need not bother about being food poisoned. However, beyond it their daily practices have to change drastically: they must avoid certain food and hope that the medications they have brought from Europe are helping, so that they do not have to rely on local doctors. However, it is not possible to pin down this threshold precisely to a particular point in space. Moreover, no institution marks this threshold: there are no political or administrative rules to confirm that, by passing this threshold, an individual comes under a different rule; yet such thresholds are more relevant for the mobile individuals than any state border.

\section{Conclusions: alternative geographies and cosmopolitanism}

The mobile professionals I studied move within strongly de-territorialized networks of the ' $U N$ family of organizations', of communication, transportation and hotel and restaurant chains. These networks mobilize people, and disembed them from particular local conditions to some extent. Next to using them, the mobile professionals apply a number of 
strategies to 'regulate' their exposure to the local people and sites. Nevertheless, in many situations, they display an intercultural competence which allows them to socialize with people across ethnic and national boundaries, let it be in place of residence or within their employment context, and which goes hand in hand with their cosmopolitan identities and aspirations. This cosmopolitan practice is underpinned by a cosmopolitan ideal that all people deserve equal treatment, attention and chances regardless their origin and residence, yet it is not without ambiguities and limitations when it comes to daily encounters. More meaningful engagements with other people and places might be taking place only within certain milieus and to particular times, and they are fragile.

The mobile professionals move primarily not between nation states but within organizational networks, and this has a consequence for how they perceive of national borders as of little relevance generally. Nevertheless, local spaces are of great importance to the individuals' choice of future residence and travel destinations beyond the assignments within the UN. Climate, diseases, armed conflicts, hygienic conditions and the populations' general attitudes towards foreigners shape the mental maps of inacceptable and impossible spaces across the world. While the de-territorialized networks of infrastructure create a geography of accessibility, the local 'negative' specificities draw a geography of exclusion. Other specificities, like food, different goods, arts put on exposure to attract tourists, draw a map of places of interest and desire, of mundane consumer-cosmopolitanism.
The daily encounters with some people, and the disjuncture between individual people and experiences and more general opinions about whole populations constitute further two geographies. The first is of people judged by their qualities and not attributes: their competence to socialize with others, and not by their ethnic origin. 'Chemistry' - sympathy, common interests, buts also a level of education and the material wealth or common aims and tasks are factors that bring people together across any other divides. The second applies national and ethnic categories to describe people and to link them to particular spaces. 'Culture' is often a common denominator for mapping people onto territories, and it brings many descriptions together: that of nationality, ethnicity, language, behaviors and attitudes. These clusters though are fragile; they can be easily broken when the actual experiences disagree with this clustering. With these many maps compete the mobile professionals tend to use one of them as a compass: a very selforiented, pragmatic, practice-driven and practice-driving geography of discontinuities, in which difference (of places rather than people) is marked by thresholds.

Any of these spatial imaginaries puts in question the dominance of ethnic and national order of space, and therefore carries a potential for cosmopolitanism. Yet the kind of cosmopolitan world-openness and people-openness that these mobile professionals display, both in the sense of the geographical distribution of their networks as well as their outlooks, is also dependent of the geographical 
imagination of the accessible space anchored in the United Nations project, which includes as many cosmopolitan as national elements (Held, 2001; 2002). A worldly sensibility that takes place locally, in a number of social interactions both face-to-face and those facilitated by technologies of distant communication is an ambiguous one. It is shaped by intercultural imaginaries shaped by transnational flows as much as bodily and material conditions. Cosmopolitanism is thus more than simply transcending the local scales to embrace the world but a matter of contesting the dominant spatial imaginary and of proliferation of alternative geographies of difference.

\section{References}

Appadurai, A., Modernity at Large: Cultural Dimensions of Globalization. Minneapolis: University of Minnesota Press, 1996.

Appiah, K. (2006) Cosmopolitanism: Ethics in a World of Strangers. New York, NY: W.W. Norton.

Bayly, S. (2007) Asian Voices in the Post-Colonial Age. Cambridge: Cambridge University Press.

Beaverstock, J. (2002) 'Transnational elites in global cities: British expatriates in Singapore's financial district'. Geoforum, 33:525-38.

Beck, U. (2004) 'Cosmopolitan realism: On the disctinction between cosmopolitanism in philosophy and the social sciences'. Global Networks, 4(2):131-56.

Beck-Gernsheim, E. (2004) Wir und die Anderen. Frankfurt a.M.: Suhrkamp. Belk. R. W. (1997) 'Been there, Done that, Bought the Souvenirs. Of Journeys and Boundary Crossing' In Turley, D. (ed.) Consumer Research. Postcards from the edge, pp. 22-45. London and New York: Routledge.

Brose, H.G. (2004) 'An Introduction towards a culture of Non-Simultaneity?' Time \& Society 13(5):5-26.

Burawoy, M. et al. (2000) Global Ethnography: Forces, Connections, and Imaginations in a Postmodern World. Berkeley, CA: University of California Press. Calhoun, C. (2003) 'The Class Consciousness of Frequent Travellers: Towards a Critique of Actually Existing Cosmopolitanism' in Archibugi, D. (ed.) Debating Cosmopolitics, pp. 86-116. London and New York: Verso.

Casey, E. S. (1998) The Fate of Place: A Philosophical History. Berkeley, CA: University of California Press.

Castells, M. (1996) The Rise of the Network Society. Oxford: Blackwell.

Comaroff, J. (1993) 'The Diseased Heart of Africa' In Lindenbaum, S. and M. Lock (eds.) Knowledge, Power and Practice: The Anthropology of Medicine and Everyday Life, pp. 305-329. Berkeley, CA: University of California Press. Delanty, G. (2006) 'The cosmopolitan imagination: Critical cosmopolitanism and social theory'. The British Journal of Sociology, 57(1):25-47.

Gellner, E. (1983) Nations and Nationalism. Ithaca, NY: Cornel University Press. 
Glaser, Barney G. (1978) Theoretical sensitivity: Advances in the methodology of grounded theory. Sociology Press (Mill Valley, Calif.)

Hannerz, U. (1990) 'Cosmopolitans and locals in a world culture'. Theory, Culture \& Society, 7(2):237-51.

Hannerz, U. (2004) Foreign News. Exploring the World of Foreign

Correspondents. Chicago, IL: The University of Chicago Press.

Harvey, D. (2000) 'Cosmopolitanism and the banality of geographical evils'.

Public Culture, 12(2):519-64.

Hebdige, D. (1990) 'Fax to the future'. Marxism Today, January:18-23.

Held, D. (2001) 'Globalization, corporate practice and cosmopolitan social standards'. Paper presented at the conference Globalisierung und Sozialstandards, 30-31 March 2001. Feldafing Starnberger See.

Held, D. (2002) 'Law of states, law of peoples'. Legal Theory, 8(2):1-44.

Hiebert, D. (2002) 'Cosmopolitanism at the Local Level: The Development of Transnational Neighbourhoods' In Vertovec, S. and R. Cohen (eds.) Conceiving Cosmopolitanism, pp. 209-25. Oxford: Oxford University Press.

Jones, P. (2007) 'Cosmopolitanism and Europe: Describing Elites or Challenging Inequalities' In Rumford, C. (ed.) Cosmopolitanism and Europe, pp. 72-86.

Liverpool: Liverpool University Press.

Kahn, B. (1987) Cosmopolitan Culture: The Gilt-Edged Dream of a Tolerant City. New York, NY: Simon and Schuster.

Kanter, R. M. (1995) World Class: Thriving Locally in the Global Economy. New York, NY: Simon and Schuster.

Kennedy, P. (2009) 'The Middle Class Cosmopolitan Journey: the Life Trajectories and Transnational Affiliations of Skilled EU Migrants in Manchester' In Nowicka, M. and M. Rovisco (eds.) Cosmopolitanism in Practice, pp. 19-36. Aldershot: Ashgate.

Kleingeld, P. (1999) 'Six varieties of cosmopolitanism in late eighteenth-century Germany'. Journal of the History of Ideas, 60(3):505-24.

Kurasawa, F. (2009) 'A message in a bottle: Bearing witness as a mode of ethicopolitical practice'. Theory, Culture \& Society, 26(1):95-114.

Lamont, M. and S. Aksartova (2002) 'Ordinary cosmopolitanisms: Strategies for bridging racial boundaries among working-class men'. Theory, Culture \& Society, 19(4):1-25.

Malkki, L. H. (1997) 'National Geographic: The Rooting of Peoples and the Territorialization of National Identity among Scholars and Refugees' In Ferguson, J. (ed.) Culture, Power, Place: Explorations in Critical Anthropology, pp. 52-74. Durham; NC: Duke University Press.

Massey, D. (2005) For Space. London: Sage.

Mignolo, W. (2000) 'The many faces of cosmo-polis: Border thinking and critical cosmopolitanism'. Public Culture, 12(3):721-48.

Molz, J. G. (2006) 'Cosmopolitan bodies: Fit to travel and travelling to fit'. Body \& Society, 12(1):1-21.

Noble G. (2009) 'Everyday Cosmopolitanism and the Labour of Intercultural 
Community' In Wise, A. and S. Velayutham (eds.) Everyday Multiculturalism, pp. 47-67. Basingstoke: Palgrave Macmillan.

Nowicka, M. (2006) Transnational Professionals and Their Cosmopolitan Universes. Frankfurt a.M. and New York: Campus.

Nowicka, M. (2007) 'Mobile locations. Construction of home in the group of transnational professionals'. Global Networks, 7(1):69-86.

Nowicka, M. (2008) 'Do You Really Talk about Emotions on the Phone...?'

Content of Distance Communication as a Structuring Moment of the Modern

World Society' In Anghel, R., Gerharz, E., Rescher, G. and M. Salzbrunn (eds.) The

Making of World Society. Perspectives from Transnational Research, pp. 253-274.

Bielefeld: Transcript.

Nowicka, M. and R. Kaweh (2009) 'Looking at the Practice of the UN

Professionals: Strategies of Managing Differences and the Emergence of a

Cosmopolitan Identity' In Nowicka, M. and M. Rovisco (eds.) Cosmopolitanism in

Practice, pp. 51-72. Aldershot: Ashgate.

Noyes, J. K. (2006) 'Goethe on cosmopolitanism and colonialism: Bildung and the dialectic of critical mobility'. Eighteenth-Century Studies, 39(4):443-62.

Sassen, S. (1996) De-facto Transnationalizing of Immigration Policy. Florence:

Robert Schuman Center Papers.

Simmel, G. (1908) 'Exkurs über den Fremden' In Simmel, G. Soziologie.

Untersuchungen über die Formen der Vergesellschaftung, pp. 509-512. Berlin:

Duncker \& Humblot Verlag.

Sklair, L. (2001) The Transnational Capitalist Class. Oxford: Blackwell.

Skrbis, Z. and I. Woodward (2007) 'The ambivalence of ordinary cosmopolitanism: Investigating the limits of cosmopolitan openness'. The Sociological Review, 55(4):730-747.

Strauss, A. and Corbin, J. (1990) Basics of Qualitative Research: Grounded Theory Procedures and Techniques. Sage Publications, Inc; 2nd edition.

Szerszynski, B. and J. Urry (2006) 'Visuality, mobility and the cosmopolitan: Inhabiting the world from afar'. British Journal of Sociology, 51(1):113-132. Thompson, C. J. and S. K. Tambyah (1999) 'Trying to be cosmopolitan'. The Journal of Consumer Research, 26(3):214-241.

Vertovec, S. (2009) 'Cosmopolitanism in attitude, practice and competence'. MMG Working Paper 09-08. Göttingen: Max-Planck-Institute for the Study of Religious and Ethnic Diversity.

Werbner, P. (1999) 'Global pathways: Working class cosmopolitans and the creation of transnational ethnic worlds'. Social Anthropology, 7(1):17-35.

Werbner, P. (2008) 'Introduction: Towards a New Cosmopolitan Anthropology' in Werbner, P. (ed.) Anthropology and the New Cosmopolitanism, 1-29. Oxford: Berg. Wessendorf, S. (2009) 'Commonplace diversity: Social interactions in a superdiverse context'. MMG Working Paper 10-11. Göttingen: Max-Planck-Institute for the Study of Religious and Ethnic Diversity.

Wise, A. and S. Velayutham (2009) (eds.)Everyday multiculturalism. Basingstoke: Palgrave Macmillan. 